\title{
Development of Structural Mediation Model of Innovative Strategy, Employees' Job Performance and Technology for UAE Government Sector
}

\section{Mohamed Ahmed Darwish Abdulla Lari, ${ }^{1,2}$, Norhadilah Abdul Hamid ${ }^{2}$, Darwish Ahmed Darwish Abdulla Lari ${ }^{1,3}$}

\author{
${ }^{1}$ Faculty of Business and Technology Management, \\ Universiti Tun Hussein Onn Malaysia (UTHM), Batu Pahat, Johor, 86400 Parit Raja, MALAYSIA \\ ${ }^{2}$ Abu-Dhabi Police (GHQ ), Al morour, Abu Dhabi, United Arab Emirates \\ ${ }^{3}$ Abu Dhabi Transmission \& Despatch Company, Abu Dhabi, United Arab Emirates \\ *Corresponding Author
}

DOI: https://doi.org/10.30880/ijscet.2020.11.02.023

Received 30 July 2020; Accepted 30 August 2020; Available online 02 September 2020

\begin{abstract}
This study established a relationship of innovations and employees' job performance in the government sector and also the mediating effect of technology towards the relationship. It adopted quantitative approach where data was collected through questionnaires survey and analyzed statistically. The questionnaire survey utilized simple random sampling methods among UAE government employees. A total of 300 questionnaires were distributed randomly and 265 were returned indicates $88.3 \%$ response rate. The collected data was then used to develop and assess SEM-AMOS mediation model. The results found that all the direct relationships reported a positive effect. It also found that the innovation dimension constructs and technology mediating construct having explained $84 \%$ variation in employees' job performance constructs. For indirect/mediation effect, it was found that technology does not show any mediation effect on the relationship between innovation and job performance constructs. This implies that technology does not mediate the relationship between innovation strategies and the employees' job performance. It also implies that for an effective employees' job performance core attention to building and managing an innovation approach is required in the UAE government sector. Thus, innovation strategies give more influence to employees' job performance in the government sector through the distinctive capabilities of UAE ministry employees.
\end{abstract}

Keywords: Innovation, job performance, technology

\section{Introduction}

Driven by global competition to improve service delivery, the UAE government in latest decade has initiated the transformation of the public sector to assist the country as a center for business excellence in the Middle East. The public sector needs continuous improvement in the employees' performance to deliver high-quality services as stated by Suliman \& Alkathairi (2013). Besides that the sector has to overcome the challenges faced on the existing practices and reviewing the performance measurement system of the public sector administration (Almansoori, 2011; Turkyilmaz et al., 2011). It also needs to address problems like lack of effective and efficient employees' performance; 
lack of creativity components; innovation, competitiveness and profitability in the UAE public sector (Suliman \& Alkathairi, 2013; Mohammed et al., 2018). There many studies on employee's job performance in the public sector but are concentrated on management commitment and hygiene factors (Suliman \& Akathairi, 2013); performance assessment (Almansoori, 2011); employee engagement and loyalty (Ibrahim \& Falasi, 2014); employees' remuneration and incentives (Al Naqbi et al., 2018).

However, there is a lack of study on the effect of innovation to employee job performance where this study was intended to fill. Hence this study was to establish the relationship between innovation strategies with employees' job performance for the UAE government sector. The innovation components used in this study are adopted from Oslo Manual developed by the OECD and the European Commission in 2005, which describes four types of innovations namely product and services innovations, process innovations, organizational innovation, and marketing innovations. While for job performance factors, it could be seen from many perspectives but this study considered the dimension of job performance into four groups namely task performance, contextual performance [interpersonal], contextual performance [organizational] and adaptive performance (Gunday et al., 2011; Weisburd \& Braga, 2019). The study further explored technology as the mediating role on the relationship between innovation approach and employee job performance (Rosrofli \& Kamal Ariffin, (2014); Hamidu et al., (2015); Fagot-Bouquet et al., 2016) which made the study novel.

\section{Methodology}

Literatures provide evidences that innovation drives from the human resource practices in which employee behavior and attitude influenced the innovation (Awan et al, 2015). Variety of human resource practices support the employee to get innovative or competences. However, employees behave corresponding with the way the organization shows commitment to them as individual. Therefore, when organization wants employees to work innovatively then it needs to focus on creating commitment to the workforce (Awan et al, 2015).. This is because innovation is an important way to overcome the challenges in the current rapidly changing environment and employees highly influence the innovation performance of organization.

This study was applied to the UAE government sector to ascertain the Role of Innovation Strategies on Employees' Job Performance. A total of 300 structured questionnaires were distributed to the sample of the Ministry of Culture, Youth and Community Development of UAE staffs to find out the effects of innovations on employees; job performance of which 260 responses were found valid. The collected data were used in the development of Analysis of Moment Structures Equation Modelling (AMOS-SEM) model which was based on the framework model and the hypotheses postulated for this research as Fig 1.

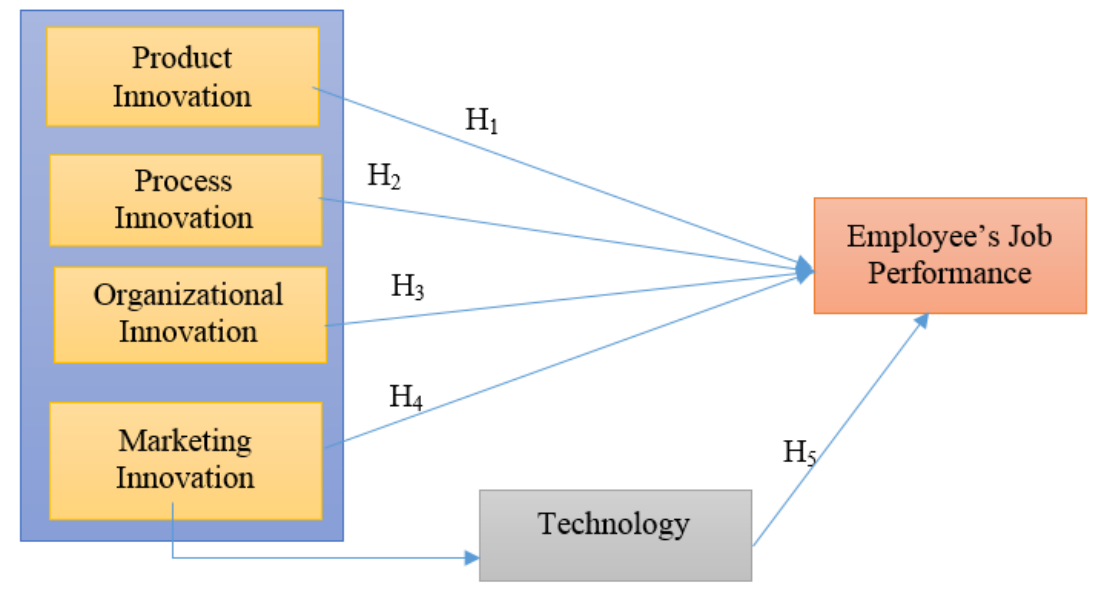

Fig 1 - Conceptual model

The framework model of figure 1 consists of innovation strategy having four independent constructs which are product innovation, process innovation, organizational innovation and marketing innovation; one mediating construct which is technology and one dependent construct which is employee's job performance. The hypotheses of this model are as follow;

H1: Product innovation has a positive relationship with job performance

$\mathrm{H} 2$ : Process innovation has a positive relationship with job performance

H3: Organizational innovation has a positive relationship with job performance

H4: Marketing Innovation has a positive relationship with job performance

H5: Technology Mediate the relationship of innovation strategy and job performance 


\section{Measurement Model Assessment}

The assessment of measurement model is conducted through Confirmatory factor analysis (CFA) using AMOSSEM software. It was conducted by adopting the recommended CB-SEM methodological process found in the multivariate texts (Hair, et al, 2010; Byrne, 2010; Kline, 2011). The analysis was conducted by specifying the model, model identification, parameter estimation, assessment of model's goodness-of-fit and lastly, re-specification of the model. Additionally, at each stage of the analysis, the validity of the models was evaluated based on the established criteria for CB-SEM evaluation presented in Table 1.

Table 1 - Recommended Goodness-of-fit Indices and acceptance levels (Awang, 2012; Kline, 2011; Byrne, 2010)

\begin{tabular}{lll}
\hline Index Category & Indices & Acceptable level \\
\hline Absolute fit & Chisq. & $\mathrm{P}<0.05$ \\
Absolute fit & RMSEA & Value $<0.08$ \\
Absolute fit & GFI & Value $>0.90$ \\
Incremental fit & AGFI & Value $>0.90$ \\
Incremental fit & CFI & Value $>0.90$ \\
Parsimonious fit & Chisq./df & Value $<5.0$ \\
\hline
\end{tabular}

Then maximum likelihood estimation (MLE) method was used to estimate the parameters of a statistical model given observations by finding the parameter values that maximize the likelihood of making the observations given the parameters. Hence, the constructs in this framework model which are the measurement and structural models were evaluated according to the established goodness-of-fit indices as presented in Table 1.

\subsection{Assessment of individual construct}

In this study the measurement model comprises of 9 individual constructs namely product innovation; process innovation; organizational innovation; marketing innovation; task performance; contextual performance interpersonal; contextual performance organizational; adaptive performance and technology. For product innovation (PI), the measurement model was constructed using seven (7) indicators which represented the measurement items for the construct. Using the AMOS graphic, the validity of the measurement model was assessed by examining the factor loadings, the squared multiple regression (R2) and the fitness indices. For a model to be considered as valid, the literature suggests that factor loading and R2 should not be less than 0.50 and 0.30 respectively (Kline, 2011; Byrne, 2010). Hair et al (2011) suggested that any factor/indicator having values less than the recommended minimum should be deleted from the measurement model. In line with the prescribed procedure, the measurement model for Product Innovation was evaluated as figure 1 and found that the seven indicators values within the recommended thresholds. However, examination of the goodness-of-fit indices revealed that the measurement model does not meet the requirement for model acceptance. Specifically, the RMSEA and Chi sq/df reported values far greater than the recommended thresholds. Similarly, both NFI and GFI reported values less than the recommended .90 , hence indicating that model re-specification is required.

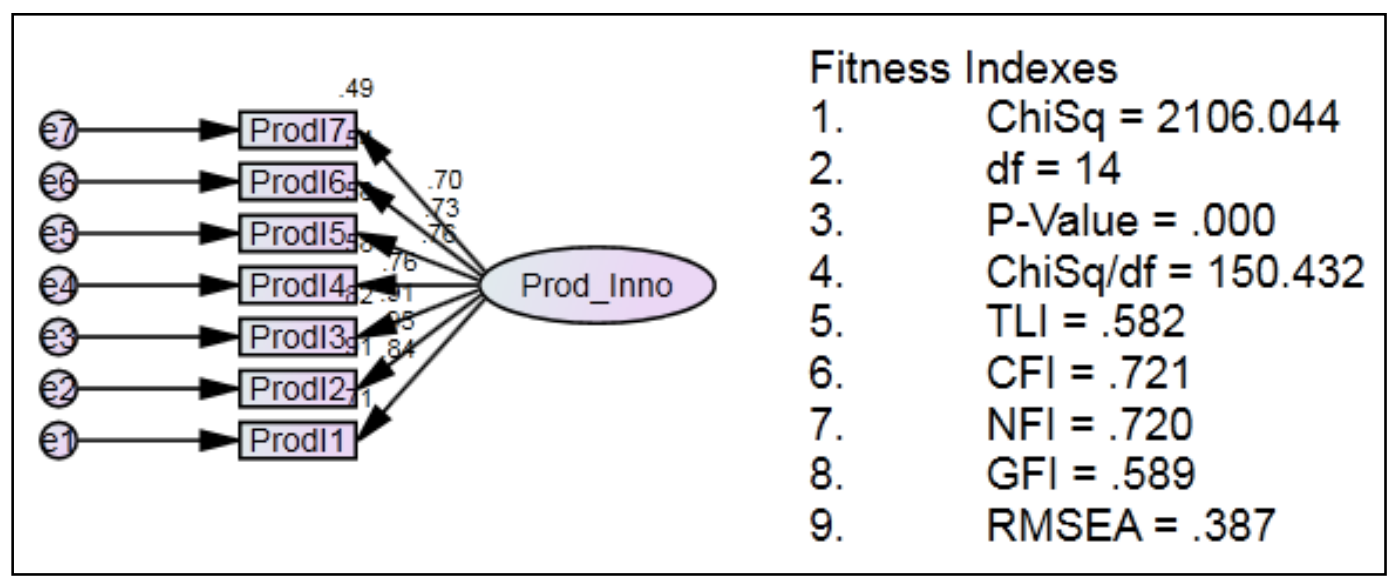

Fig. 2 - Initial measurement model for product innovation

Fig. 2 shows the re-specified measurement model for product Innovation. Upon freeing up some parameters in the initial model by co-varying two error terms e3 and 36, the desired model fitness is achieved. All the model fitness indices returned values within the acceptable thresholds. RMSEA reported .078 , Chi sq/df=2.612 while GFI and NFI 
reported values greater than the recommended value of .90 . Thus, the final model is accepted and retained for inclusion in the structural model.

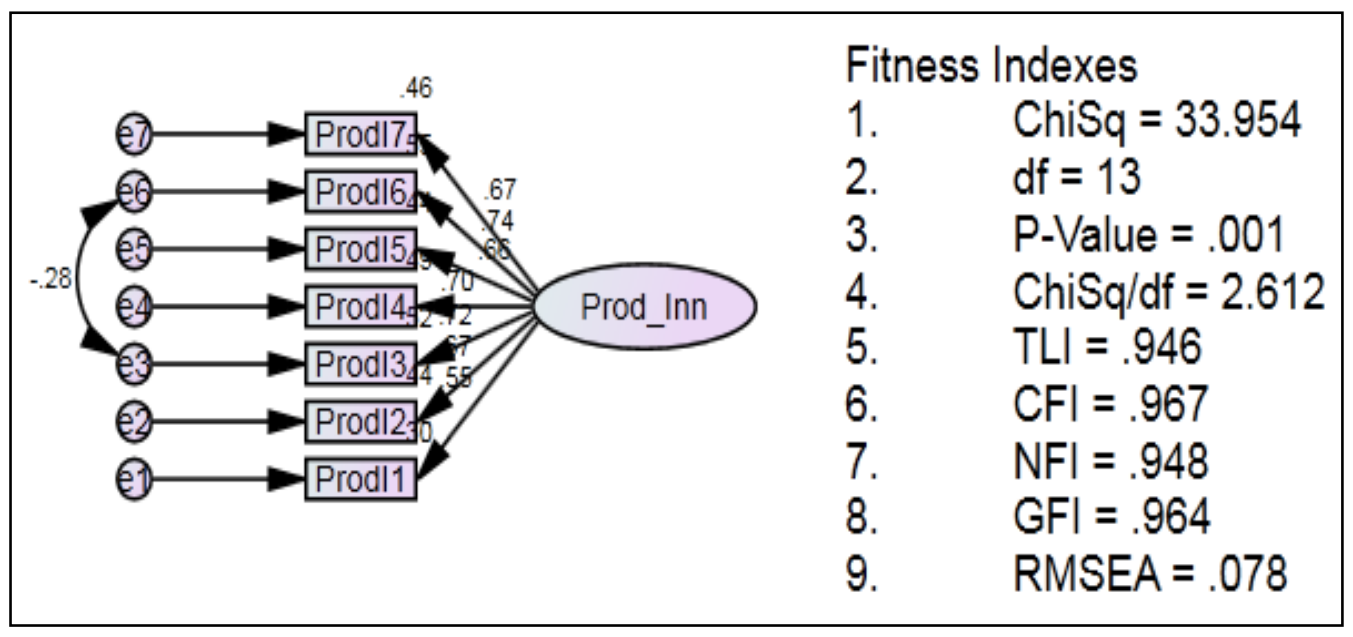

Fig. 3 - Final measurement model Product Innovation

The same procedures were conducted for the other eight individual constructs. Having established the validity and model of fit of the individual constructs, it is necessary to assess the validity of the entire measurement model of the research prior to evaluating the structural model. The rationale for conducting this analysis was to establish the validity of all the constructs in unison. The validity of the entire measurement model was assessed by examining the convergent validity and discriminant validity of the constructs in the model.

\subsection{Assessment of Entire Measurement Model}

According to Hair et al (2010), two parameters can be used which are convergent validity and discriminant validity in assessing the entire measurement model. Convergent validity is a measure of the degree to which the items or indicators of a construct are correlated with the construct. While discriminant validity measures the degree to which a construct is distinct from other constructs in the model.

In CFA SEM analysis, the convergent validity of construct is assessed by Bentler_Bonett coefficient (NFI). Recommended threshold for convergent validity using the NFI index is 0.90 (Hair, et al, 2010; Kline, 2011; Byrne, 2010). Using the factor loading and the NFI criteria, the convergent validity of the individual final measurement models is as in Table 2.

Table 2 - Convergent validity measures of the entire final models

\begin{tabular}{|c|c|c|c|c|c|}
\hline \multirow{2}{*}{ No } & \multirow{2}{*}{ Construct } & \multirow{2}{*}{$\begin{array}{c}\text { Residual items } \\
\text { number }\end{array}$} & \multicolumn{2}{|c|}{ Factor loading } & \multirow{2}{*}{ NFI Index } \\
\hline & & & Lowest FL & Highest FL & \\
\hline 1 & Product Innovation & 7 & .546 & .741 & .948 \\
\hline 2 & Process Innovation & 4 & .558 & .778 & .981 \\
\hline 3 & Organisational Innovation & 5 & .634 & .742 & .977 \\
\hline 4 & Marketing Innovation & 7 & .676 & .798 & .961 \\
\hline 5 & Task Performance & 5 & .871 & .988 & .999 \\
\hline 6 & $\begin{array}{l}\text { Contextual Performance } \\
\text { Interpersonal }\end{array}$ & 4 & .784 & .955 & .998 \\
\hline 7 & $\begin{array}{l}\text { Contextual Performance } \\
\text { organizational }\end{array}$ & 4 & .699 & .917 & .990 \\
\hline 8 & Adaptive Performance & 6 & .676 & .793 & .967 \\
\hline 9 & Technology & 7 & .696 & .813 & .967 \\
\hline
\end{tabular}

Table 2 indicates that all constructs satisfy the acceptable threshold. For discriminant validity, it is achieved when the squared inter-construct correlations associated with a particular construct are greater than the corresponding interconstruct correlation estimates with other constructs (Hair et al, 2010). The recommended threshold for AVE is $\geq 0.50$ (Hair, et al. 2014) and the discriminant validity of this study is as in table 3. 
Table 3 - Discriminant validity of the entire final model

\begin{tabular}{lcccccc}
\hline & JP & Pro_Inn & Mkt_Inn & Proc_Inn & Org_Inn & Techno \\
\hline JP & $\mathbf{0 . 7 8 1}$ & & & & & \\
Pro_Inn & 0.006 & $\mathbf{0 . 8 4 3}$ & & & & \\
Mkt_Inn & -0.010 & 0.815 & $\mathbf{0 . 8 3 9}$ & & & \\
Proc_Inn & -0.239 & 0.708 & 0.704 & $\mathbf{0 . 7 9 2}$ & & \\
Org_Inn & 0.340 & 0.619 & 0.662 & 0.726 & $\mathbf{0 . 8 0 3}$ & \\
Techno & 0.581 & -0.253 & -0.126 & 0.065 & 0.409 & $\mathbf{0 . 8 4 4}$ \\
\hline
\end{tabular}

Table 3 shows the AVE of each construct at the diagonal while the off-diagonal values represent the correlation coefficients between the constructs. Based on the recommended threshold, all the AVEs are greater than 0.50 and each AVE value is higher than any correlation with other construct, hence indicating the achievement of discriminant validity.

\section{Structural Model Evaluation}

Once the entire measurement model has achieved the assessment criteria, the model can then be assessed at the structural component. The following stage is to conduct path analysis to evaluate the structural part of the model. It assessed the mediating relationship that is the exogenous variables which are product innovation, market innovation, process innovation and organizational innovation with the mediator variable which is the technology and the exogenous variable which is the job performance.

At the initial assessment of the structural model, it was found that some indexes failed to meet the acceptable level. All the observed factor loadings and their corresponding square multiple regression meet the required thresholds of 0.50 and 0.30 respectively. In respect of the fit indexes, the RMSEA, CFI, and GFI do not satisfy the criteria for acceptance while only the p-value reported values within the acceptable limit. This suggests that model re-specification was required. Then re-specification of the model was carried out by freeing off some parameters through co-variation and the results are as in Fig 4

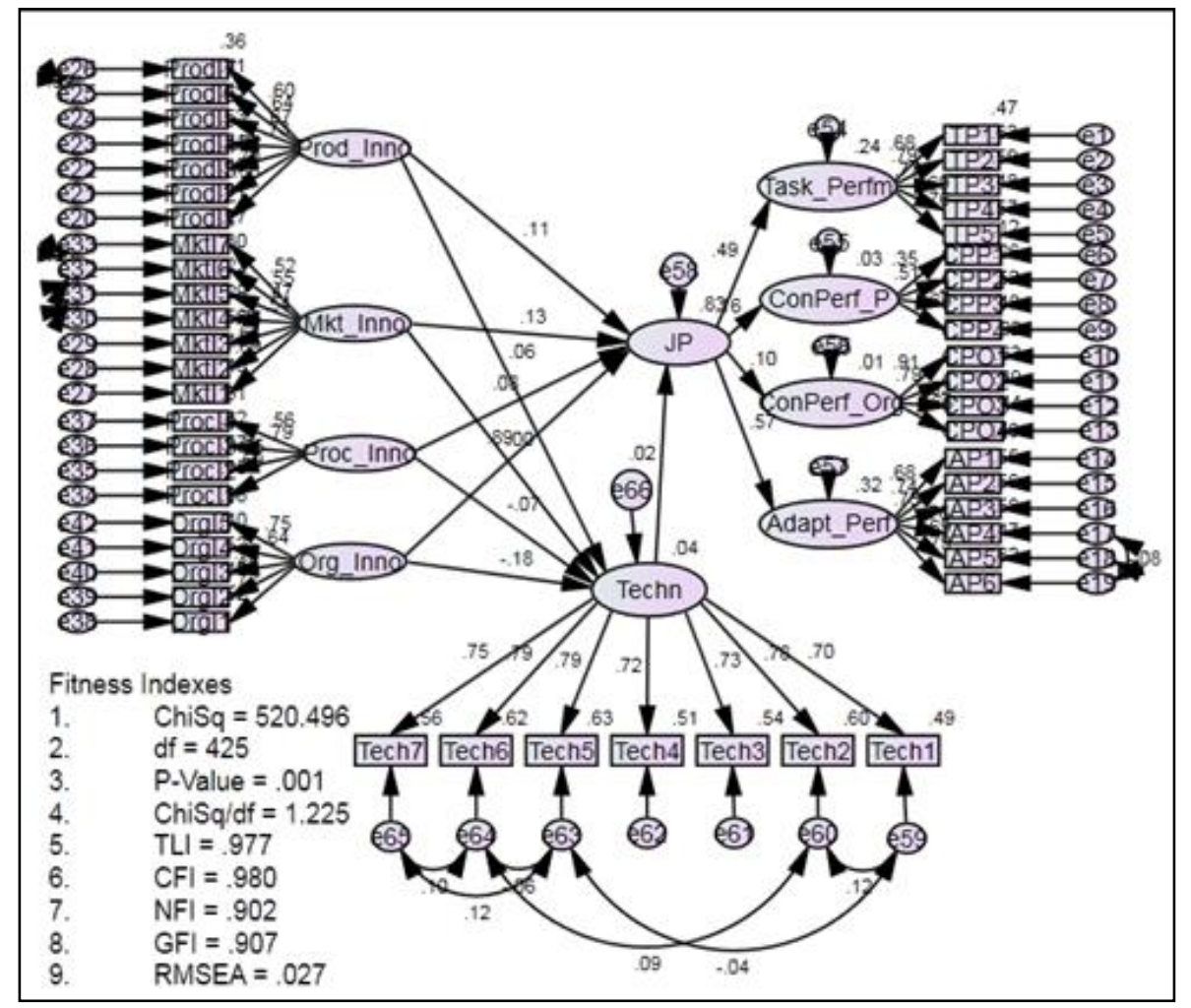

Fig. 4 - Final structural model

At structural modelling in CFA, the model has to meet up with the criteria for model fit. However, Hair et al (2010), Kline (2011) and Byrne (2010) suggested that a model should satisfy the requirement of at least one index from each of the index categories, that is, absolute fit, incremental fit and parsimonious fit indices. In respect of the RMSEA, 
Byrne (2010) pointed out that a range of 0.08 to 1.00 is also acceptable in assessing model fit. Hence from the figure 4 it can be concluded that the model has achieved indices criteria as in table 4

Table 4 - Structural Model's Achievement

\begin{tabular}{lllc}
\hline Index Category & Indices Used & Acceptable level & Model's Achievement \\
\hline Absolute fit & RMSEA & Value $<0.08$ & $\mathbf{0 . 0 2 7}$ \\
Absolute fit & GFI & Value $>0.90$ & $\mathbf{0 . 9 0 7}$ \\
Incremental fit & CFI & Value $>0.90$ & $\mathbf{0 . 9 8 0}$ \\
Parsimonious fit & Chi sq./df & Value $<5.0$ & $\mathbf{1 . 2 2 5}$ \\
\hline
\end{tabular}

Results from Table 4 indicates that all the indices of the final model have achieved the assessment criteria.

\section{Hypothesis Testing}

After completing the assessment of the measurement and structural mode, the following step is to check the model according to the proposed hypotheses. In the case of mediation model there are two types of hypotheses which are direct relationship and indirect relationship.

\subsection{Direct Relationship}

For the direct relationship, the path relationship/hypothesis as in Table 5 presented the standardized regression coefficients of the direct relationships of product innovation, market innovation, process innovation, organizational innovation and technology with the endogenous construct job performance.

Table 5 - Results of The Direct Relationship

\begin{tabular}{|c|c|c|c|c|c|}
\hline Path relationship & Estimate & S.E & C.R. & P-value & $\mathbf{R}^{2}$ \\
\hline JP๘Prod_Inno & .111 & .107 & 1.201 & .230 & \multirow{5}{*}{.84} \\
\hline $\mathrm{JP} \leftarrow$ Mkt_Inno & .125 & .092 & 1.326 & .185 & \\
\hline 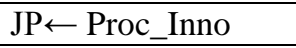 & .084 & .103 & .889 & .374 & \\
\hline JP־Org_Inno & .892 & .064 & 5.517 & $* * *$ & \\
\hline $\mathrm{JP} \leftarrow \mathrm{Techn}$ & .016 & .039 & .174 & .862 & \\
\hline 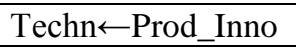 & .062 & .187 & .877 & .381 & \multirow{4}{*}{.042} \\
\hline Techn $\leftarrow$ Mkt_Inno & -.004 & .161 & -.052 & .959 & \\
\hline Techn ŁProc_Inno & -.074 & .182 & -1.027 & .305 & \\
\hline Techn $\leftarrow$ Org_Inno & -.180 & .066 & -2.482 & .013 & \\
\hline
\end{tabular}

From Table 5, it is shown that all the direct relationships reported a positive effect. However, only the path JP Org_Inno indicated a statistically significant effect $(\beta=.892 ; \mathrm{CR}=5.517 ; \mathrm{p}>.05)$ the remaining path coefficients are not statistically significant. Altogether, the four exogenous constructs together with the mediating construct explained $84 \%$ variation in job performance. Additionally, the table also presents the path relationship between the mediator construct, technology and the four exogenous constructs (product innovation, market innovation, process innovation, and organizational innovation). From the result, it is shown that collectively the four exogenous constructs explained less than $1 \%$ variability in technology.

\subsection{Indirect Relationship}

To test the mediation effect of technology on the relationship between product innovation, market innovation, process innovation, organizational innovation and job satisfaction, the bootstrapping method is used. The bootstrapping method has been described as the most effective method of testing mediation against the Sobel Test method (Hayes, 2014). The procedure involved re-sampling of the working data set between 500 and 1000 times which a sampling distribution from which the total effect, the direct effect and indirect effect estimates and their corresponding $95 \%$ confidence interval values are produced. The algorithm also estimates the lower and upper limits as well as the twotailed significant values for the effects. Table 6 shows the bootstrapping result for testing the mediation effect of technology in the research model. 
Table 6 - Results of Indirect Relationship

\begin{tabular}{|c|c|c|c|c|}
\hline \multirow{2}{*}{ Path relationship } & \multirow{2}{*}{$\begin{array}{c}\beta \text { value } \\
\text { Estimate }\end{array}$} & \multicolumn{2}{|c|}{ CI value } & \multirow{2}{*}{ P-value } \\
\hline & & Lower Bounds & Upper Bounds & \\
\hline 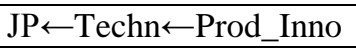 & .001 & -.013 & .001 & .523 \\
\hline $\mathrm{JP} \leftarrow$ Techn$\leftarrow \mathrm{Mkt}$ Inno & .000 & .000 & .000 & .361 \\
\hline $\mathrm{JP} \leftarrow$ Techn$\leftarrow$ Proc_Inno & -.001 & -.003 & .002 & .442 \\
\hline $\mathrm{JP} \leftarrow$ Techn$\leftarrow$ Org_Inno & -.001 & .002 & .001 & .497 \\
\hline
\end{tabular}

Table 6 shows that technology does not show any mediation effect on the relationship between product innovation and job performance $(\beta=.001 ; 95 \% \mathrm{CI}:-.013 \sim .001 ; \mathrm{p}=.523)$. Similarly, job performance is shown to have no mediation effect on the relationship between market innovation and job performance $(\beta=-.000 ; 95 \%$ CI: $.000 \sim .000 ; p=.361)$. In addition, technology does not mediate the relationship between process innovation, and organizational innovation and job performance with respective statistics as in the table.

\section{Conclusion}

This study developed and assessed the mediation model using collected data from questionnaire survey amongst the staff in the Ministry of Culture, Youth and Community Development of UAE. It found that organizational innovation, product innovation, process innovation and marketing innovation has a negative relationship with technology. Moreover, organizational innovation, product innovation, process innovation and marketing innovation were positively associated with the employees' job performance. Unfortunately, this study was unable to establish the suggested positive impact of product innovation, process innovation and marketing innovation on technology maybe to the collected data were not strong enough to establish the relationship. Hopefully this study can be applicable to improve the job performance in the UAE and further explore by incorporating other variables to the mediation model

\section{References}

Al Naqbi, R. A. K.,Yusoff, R. M., \& Dr. Ismail, F. B (2018). The Effect of Incentive System on Job Performance Motivation as Mediator for Public Sector Organization in UAE. International Journal of Engineering \& Technology,7(4.7), 380-388

Almansoori, M. E. A. (2011). Perceptions of public sector staff of an organisation performance measurement system: a case study of the Abu Dhabi police service (Doctoral dissertation, Liverpool John Moores University)

Awan, M. S., Javed, M., \& Waqas, M. (2015). Migration, remittances, and household welfare: Evidence from Pakistan. The Lahore Journal of Economics, 20(1), 47

Awang, Z. (2012). Structural equation modeling using AMOS graphic. Penerbit Universiti Teknologi MARA

Byrne, B. M.(2010). Structural equation modeling with AMOS: Basic concepts, applications, and programming (2nd ed.). New York: Routledge

Fagot-Bouquet, L., Audigier, R., Dhome, Y., \& Lerasle, F. (2016, October). Improving multi-frame data association with sparse representations for robust near-online multi-object tracking. In European Conference on Computer Vision (pp. 774-790). Springer, Cham

Gunday, G., Ulusoy, G., Kilic, K., \& Alpkan, L. (2011). Effects of innovation types on firm performance. International Journal of production economics, 133(2), 662-676

Hair Jr, J. F., Black, W. C., Babin, B. J., Anderson, R. E., \& Tatham, R. L. (2010). SEM: An introduction. Multivariate data analysis: A global perspective, 5(6), 629-686

Hair, J. F., Celsi, M., Money, A., Samouel, P., \& Page, M. (2011). Essentials of business research methods (2nd ed.). Armonk, NY: ME Sharpe

Hair, J. F., Hult, G. T. M., Ringle, C. M., \& Sarstedt, M. (2014). A primer on partial least squares structural equation modeling (PLS-SEM). Thousand Oaks: Sage 
Hamidu, A., Haron, M., \& Amran, A. (2015). Corporate social responsibility: A review on definitions, core characteristics and theoretical perspectives. Mediterranean Journal of Social Sciences, 6(4), 83-95

Hayes, A. F., \& Preacher, K. J. (2014). Statistical mediation analysis with a multicategorical independent variable. British journal of mathematical and statistical psychology, 67(3), 451-470

Ibrahim, M.,\&Falasi, S. (2014). Employee loyalty and engagement in UAE public sector. Employee Relations, 36(5), 562-582

Kline, R. B. (2011). Principles and practice of structural equation modeling (3rd ed.). New York: The Guilford Press

Mohamed, M. S., Khalifa, G. S., Nusari, M., Ameen, A., Al-Shibami, A. H., \& Abu-Elhassan, A. E. (2018). Effect of Organizational Excellence and Employee Performance on Organizational Productivity Within Healthcare Sector in the UAE. Journal of Engineering and Applied Sciences, 13(15), 6199-6210

Rosrofli, M. A., \& Kamal Ariffin, K. A. (2014). The factor that influence employees awareness towards the benefits provided by SOCSO a case study: operation division at Honda Head Office (Malacca Manufacturing Plant)

Suliman, A. and Alkathairi, M. (2013), "Organizational justice, commitment and job performance in developing countries: the case of the UAE”, Employee Relations, Vol. 35 No. 1, pp. 98-115

Turkyilmaz, A., Akman, G., Ozkan, C., \& Pastuszak, Z. (2011). Empirical study of public sector employee loyalty and satisfaction. Industrial Management \& Data Systems, 111(5), 675-696

Weisburd, D., \& Braga, A. A. (Eds.). (2019). Police innovation: Contrasting perspectives. Cambridge University Press 